\title{
Cognitive reserve and emotional and current cognitive performance of older adults with different cultural background - preliminary study
}

\author{
Rezerwa poznawcza a aktualne funkcjonowanie poznawcze i emocjonalne osób w okresie \\ późnej dorosłości z uwzględnieniem odmienności kulturowych - doniesienie wstępne
}

\author{
Department of Clinical Psychology and Neuropsychology, Institute of Psychology, Maria Curie-Skłodowska University, Lublin, Poland \\ Correspondence: Anna Boiko, Institute of Psychology, Maria Curie-Skłodowska University, pl. Litewski 5, 20-080 Lublin, Poland, ORDIC ID: orcid.org/0000-0002-5816-3270, e-mail: anna.boiko@wp.pl
}

Zakład Psychologii Klinicznej i Neuropsychologii, Instytut Psychologii, Uniwersytet Marii Curie-Skłodowskiej w Lublinie, Lublin, Polska

Adres do korespondencji: Anna Boiko, Instytut Psychologii UMCS, pl. Litewski 5, 20-080 Lublin, ORDIC ID: orcid.org/0000-0002-5816-3270, e-mail: anna.boiko@wp.pl

\begin{abstract}
Background: A cognitive reserve level has a significant impact on changes in cognitive performance in the process of natural aging. The cognitive reserve level consists of multiple variables, which are often shaped by the current sociopolitical environment, including a socioeconomic status, the level of education, and occupation. Aim of the study: A comparison of the cognitive reserve and selected cognitive abilities of seniors from different cultures (Poland and Ukraine), and the analysis of the impact of both variables (cognitive reserve and cultural background) on the level of current cognitive abilities. Material and methods: The study was conducted in two countries (Poland and Ukraine) and included 30 participants aged 60-93. Research tools used in the study were the following: Montreal Cognitive Assessment (MoCA), subtests: Vocabulary and Digit Span from Wechsler Adult Intelligence Scale-Revised (WAIS-R), Written Metaphor test in RHLB-PL (Right Hemisphere Language Battery), semantic and emotional fluency tasks, Benton Visual Retention Test, Satisfaction with Life Scale (SWLS), Beck Depression Inventory-II (BDI-II) and the author's questionnaire for the cognitive reserve assessment. Results: Polish seniors obtained a significantly higher overall score in MoCA, verbal fluency tasks, Benton Visual Retention Test and in MoCA subtests: Language, Abstraction and Delayed Recall. The results of a two-way analysis of variance showed a significant effect of the cultural background and/or the cognitive reserve on the level of language skills (MoCA: Language), abstract thinking (MoCA: Abstraction), and the level of depression (BDI-II). Conclusions: Cognitive reserve factors show a diverse relationship with different spheres of human functioning in different cultures, and thus their role in successful aging may be various.
\end{abstract}

Keywords: cognitive reserve, ageing, cross-cultural comparison

Streszczenie Wstęp: Poziom rezerwy poznawczej ma istotny wpływ na zmiany kondycji poznawczej w procesie naturalnego starzenia się. Na poziom rezerwy poznawczej wpływają z kolei wzajemnie powiązane i kształtowane od wczesnych lat rozwoju zmienne: status socjoekonomiczny, poziom edukacji czy aktywność zawodowa, często uwarunkowane cechami środowiska społeczno-ekonomicznego. Cel: Celami badania były porównanie zasobów poznawczych i wybranych aktualnych możliwości poznawczych seniorów wywodzących się z odmiennych warunków kulturowych - w Polsce i na Ukrainie - oraz ustalenie wpływu obydwu zmiennych, czyli poziomu rezerwy poznawczej i pochodzenia kulturowego, na poziom aktualnych możliwości poznawczych. Materiał i metoda: Badanie przeprowadzono na terenie dwóch krajów (Polski i Ukrainy) z udziałem 30 osób w wieku 60-93 lat. Zastosowano takie narzędzia badawcze, jak: Montrealska Skala Oceny Funkcji Poznawczych (Montreal Cognitive Assessment, MoCA), podtesty Słownik i Powtarzanie Cyfr ze Skali Inteligencji D. Wechslera dla Dorosłych, wersji zrewidowanej (Wechsler Adult Intelligence Scale-Revised, WAIS-R), Test Metafor Pisanych z Baterii Testów do Badania Funkcji Językowych i Komunikacyjnych Prawej Półkuli Mózgu (RHLB-PL; Right Hemisphere Language Battery), próby fluencji semantycznej oraz emocjonalnej, Test Pamięci Wzrokowej Bentona (Benton Visual Retention Test), Skala Satysfakcji z Życia (Satisfaction with Life Scale, SWLS), Kwestionariusz Depresji BDI-II Aarona T. Becka (Beck Depression Inventory-II, BDI-II), jak również ankietę autorską, będącą podstawą oceny rezerwy poznawczej. Wykorzystano odpowiednie wersje językowe metod. Wyniki: Polscy seniorzy uzyskali istotnie wyższy ogólny wynik w MoCA, zadaniach fluencji słownej, Teście Pamięci Wzrokowej Bentona i w podtestach MoCA: Język, Abstrahowanie, 
Odroczone przypominanie. Dwuczynnikowa analiza wariancji wykazała istotny wpływ pochodzenia kulturowego i/lub rezerwy poznawczej na poziom sprawności językowej (MoCA: Język), myślenia abstrakcyjnego (MoCA: Abstrahowanie) i nasilenia nastroju depresyjnego (BDI-II). Wnioski: Czynniki kształtujące rezerwę poznawczą wykazują zróżnicowany związek z poszczególnymi sferami funkcjonowania człowieka w odmiennych kulturach, a więc ich znaczenie dla satysfakcjonującego starzenia się może być odmienne.

Słowa kluczowe: rezerwa poznawcza, starzenie się, porównania międzykulturowe

\section{INTRODUCTION}

$\mathrm{T}$ The cognitive reserve (CR) is the entirety of knowledge and skills acquired by a person in a lifetime. Studies carried out in numerous centres show that higher levels of CR not only compensate for cognitive deficits by masking and postponing the expression of dementia symptoms, but also $r$ elieve cognitive deficits associated with the process of natural aging (Stern, 2009, Stern et al., 2005). Analyses regarding the significance of CR for satisfactory aging are important due to the phenomenon of double aging of the society, i.e. the increase in the percentage of seniors aged $60+$, and among them - people aged 80 and more (World Health Organization, 2015). This trend is visible in Europe (Börsch-Supan et al., 2013), especially Poland, where the number of people aged $65+$ increased by over 3\% in the years 2007-2017 (Eurostat - Statistics Explained) and Ukraine, where the percentage of people aged $60+$ will rise from $15.5 \%$ in 2010 to $26.1 \%$ in 2060 , according to forecasts (Kupets, 2014). These demographic phenomena pose an increasing challenge to the medical and social care systems of the European countries, also since the risk of developing dementia is growing with age due to hypertension, metabolic diseases or genetic determinants (e.g. APOE e4 allele) (Barnes et al., 2009). This is the reason for the CR interest, which is partly created by factors considered modifiable, i.e. lifestyle.

A higher CR level promotes better cognitive performance in the process of natural aging. The higher level of CR consists of the following variables, which are interrelated and shaped from the early years of development: high socioeconomic status, high level of education (Opdebeeck et al., 2016; Singh-Manoux et al., 2011), rich life activity, including high level of physical, professional and social activity (Byczewska-Konieczny et al., 2013; Cheng, 2016; Ward et al., 2015), good health and a healthy lifestyle (Cadar et al., 2017; Scarmeas and Stern, 2003). Some reports indicate that the CR level, which determines cognitive performance in the late stages of life, is determined by skills and competences which are congenital or acquired mainly in the early childhood (Armstrong et al., 2012; Starr and Lonie, 2008). According to other studies, building the CR is possible in all phases of life, due to the specific types of activity characteristic to these phases (Malek-Ahmadi et al., 2017). Despite the discussion on how to measure the CR (MalekAhmadi et al., 2017), most of the meta-analyses showed

\section{WSTĘP}

$\mathrm{R}$ ezerwa poznawcza (cognitive reserve, $\mathrm{CR}$ ) to całokształt wiedzy i umiejętności nabytych przez człowieka w ciągu życia. Wieloośrodkowe badania wykazują, że wyższy poziom CR nie tylko pozwala kompensować deficyty poznawcze, maskując i odraczając ekspresję symptomów chorób otępiennych, lecz także łagodzi deficyty poznawcze związane z procesem naturalnego starzenia się (Stern, 2009; Stern et al., 2005). Analizy dotyczące znaczenia CR dla satysfakcjonującego starzenia się są istotne ze względu na zjawisko podwójnego starzenia się społeczeństw (double ageing), polegającego na wzroście odsetka seniorów w wieku 60+, a wśród nich - osób w wieku 80 i więcej lat (World Health Organization, 2015). Wskazany trend dotyczy Europy (Börsch-Supan et al., 2013), szczególnie zaś Polski, gdzie w latach 2007-2017 o ponad 3\% wzrosła liczba osób w wieku 65+ (Eurostat - Statistics Explained), oraz Ukrainy, gdzie prognozy przewidują wzrost odsetka osób w wieku $60+$ z 15,5\% w roku 2010 do $26,1 \%$ w 2060 (Kupets, 2014). Te zjawiska demograficzne stanowią coraz większe wyzwanie dla systemów opieki medycznej i społecznej krajów Europy, również ze względu na fakt, iż wraz $\mathrm{z}$ wiekiem rośnie ryzyko rozwoju schorzeń otępiennych w związku z nadciśnieniem tętniczym, chorobami metabolicznymi czy uwarunkowaniami genetycznymi (np. allelem APOE e4) (Barnes et al., 2009). Jest to powód zainteresowania CR, którą częściowo tworzą czynniki uznane za modyfikowalne, czyli styl życia.

Wyższy poziom CR sprzyja lepszej kondycji poznawczej $\mathrm{w}$ procesie naturalnego starzenia się. Na wyższy poziom CR składają się - wzajemnie powiązane i kształtowane od wczesnych lat rozwoju - zmienne: wysoki status socjoekonomiczny, wysoki poziom edukacji (Opdebeeck et al., 2016; Singh-Manoux et al., 2011), bogata aktywność życiowa, w tym wysoki poziom aktywności fizycznej, zawodowej i społecznej (Byczewska-Konieczny et al., 2013; Cheng, 2016; Ward et al., 2015), dobry stan zdrowia i zdrowy tryb życia (Cadar et al., 2017; Scarmeas i Stern, 2003). Część doniesień wskazuje, że o poziomie CR, warunkującym sprawność poznawczą w późnych fazach życia, decydują umiejętności i kompetencje wrodzone albo nabyte głównie we wczesnym dzieciństwie (Armstrong et al., 2012; Starr i Lonie, 2008), a inne badania - że budowanie CR jest możliwe we wszystkich fazach życia, ze względu na specyficzne dla nich rodzaje aktywności (Malek-Ahmadi et al., 2017). Pomimo dyskusji 
(education, work, hobby, intellectual, social and physical activity) on cognitive functions (especially executive and attention functions) of healthy adults and seniors (Meng and D'Arcy, 2012; Murphy and O'Leary, 2010; Opdebeeck et al., 2016). Different data were obtained by Šneidere et al. (2018) in the studies with the participation of Latvian seniors - these authors did not find a correlation between the CR and the efficiency of attention functions. A higher CR level also improves emotional functioning by protecting against the development of depression (Cadden et al., 2019; Paulson et al., 2014), positively affecting the quality of life, self-esteem and self-efficacy (Lara et al., 2017; Opdebeeck et al., 2017).

Epidemiology of dementia of various aetiologies in different regions of the world (Rizzi et al., 2014) boosted the interest in the relations between the CR, sociocultural factors and cognitive functioning in the late years of life. Study data from various sociocultural backgrounds confirmed the relationship between the low CR and a higher risk of developing dementia, regardless of other risk factors (gender, positive family history, past head injuries, genetic determinants); they also indicated a clear interaction of factors forming low CR, such as: low level of education, low economic status, bad nutrition during childhood, poor health at subsequent stages of life, chronic stress (Kalaria et al., 2008; Ojagbemi et al., 2016). Reports suggesting that many factors can be modified are more optimistic. For example: although illiteracy is a risk factor for the development of mild cognitive impairment (MCI) and dementia, this risk decreases with each year of education (Brucki and Nitrini, 2014; Farfel et al., 2013). It seems that the low level of CR is a feature observed mainly in the developing countries (including - among others - the European countries) (Kalaria et al., 2008), poor ones or in armed conflicts. The result may be a greater risk of developing MCI and dementia (Darwish et al., 2018; Fyffe et al., 2011; Ihle et al., 2018; Prince et al., 2013).

\section{MATERIAL AND METHODS}

The main objectives of the author's own research were: a) the comparison of CR and selected current cognitive and emotional capabilities of seniors derived from different cultural conditions - of Poland and Ukraine; b) the determination of the impact of both variables, i.e. the level of CR and the cultural origin, and their interaction on the current cognitive and emotional capabilities.

The research was conducted in two countries: Poland and Ukraine. Suitable language versions of research tools were prepared for each group. Volunteers were invited to participate in the study - people over 60 years of age. All participants expressed a written informed consent to participate in the study (consent of the Research Ethics Committee No. 13/2018). The exclusion criteria were the following: an interview indicating the possibility of psychiatric defects, a person's bad mood, cognitive functioning that prevented na temat sposobów pomiaru CR (Malek-Ahmadi et al., 2017) większość metaanaliz wykazała wyraźny pozytywny wpływ szeroko rozumianej aktywności życiowej (edukacji, pracy zawodowej, hobby, aktywności intelektualnej, społecznej i fizycznej) na funkcje poznawcze (szczególnie funkcje wykonawcze i uwagowe) zdrowych dorosłych i seniorów (Meng i D’Arcy, 2012; Murphy i O’Leary, 2010; Opdebeeck et al., 2016). Odmienne dane uzyskali Šneidere i wsp. (2018) w badaniach $z$ udziałem łotewskich seniorów - autorzy ci nie stwierdzili związku między CR a sprawnością funkcji uwagowych. Wyższy poziom CR poprawia też funkcjonowanie emocjonalne, chroniąc przed rozwojem depresji (Cadden et al., 2019; Paulson et al., 2014), pozytywnie wpływając na poczucie jakości życia, samoocenę i poczucie własnej skuteczności (Lara et al., 2017; Opdebeeck et al., 2017).

Epidemiologia otępień o różnej etiologii w różnych regionach świata (Rizzi et al., 2014) wzmocniła zainteresowanie relacjami między CR, czynnikami socjokulturowymi i funkcjonowaniem poznawczym w późnych latach życia. Dane $\mathrm{z}$ badań rozmaitych środowisk społeczno-kulturowych potwierdziły związek między niską CR a wyższym ryzykiem rozwoju demencji niezależnie od innych czynników ryzyka (płeć, pozytywny wywiad rodzinny, przebyte urazy głowy, uwarunkowania genetyczne); wskazały również na wyraźne interakcje czynników tworzących niską CR, takich jak: niski poziom edukacji, niski status ekonomiczny, złe odżywianie w okresie dzieciństwa, zły stan zdrowia w kolejnych etapach życia, przewlekły stres (Kalaria et al., 2008; Ojagbemi et al., 2016). Bardziej optymistyczne są doniesienia sugerujące, że wiele czynników można modyfikować. Przykładowo: chociaż analfabetyzm jest czynnikiem ryzyka rozwoju łagodnych zaburzeń poznawczych (mild cognitive impairment, MCI) i demencji, $\mathrm{z}$ każdym rokiem edukacji ryzyko to maleje (Brucki i Nitrini, 2014; Farfel et al., 2013). Wydaje się, iż niski poziom CR to cecha obserwowana głównie w krajach rozwijających się (do których zaliczono m.in. państwa Europy) (Kalaria et al., 2008), ubogich czy pozostających w konfliktach zbrojnych. Skutkiem może być większe ryzyko rozwoju MCI i demencji (Darwish et al., 2018; Fyffe et al., 2011; Ihle et al., 2018; Prince et al., 2013).

\section{MATERIA $~ I$ METODA}

Głównymi celami badań własnych były: a) porównanie zasobów poznawczych (CR) i wybranych aktualnych możliwości poznawczych i emocjonalnych seniorów wywodzących się z odmiennych warunków kulturowych - Polski i Ukrainy; b) określenie wpływu obydwu zmiennych, czyli poziomu CR i pochodzenia kulturowego, oraz ich interakcji na aktualne możliwości poznawczo-emocjonalne.

Badania były prowadzone na terenie dwóch krajów: Polski i Ukrainy. Dla każdej grupy zostały przygotowane odpowiednie wersje językowe narzędzi badawczych. Do uczestnictwa w badaniu zaproszono ochotników - osoby po 60. roku życia. Wszyscy uczestnicy wyrazili pisemną 
the test being carried out. The analysis included the results of 30 people aged 60-93: 22 women $\left(M_{\text {age }}=71.9\right.$, standard deviation, $S D=10.6)$ and 8 men $\left(M_{\text {age }}=69.6, S D=6.7\right)$. Over half of the respondents had secondary or vocational education (66.7\%), other people had tertiary education (26.7\%) or basic education (6.7\%). Most participants (86.7\%) had not been cured because of somatic and neurological diseases, including hypertension.

The CR was evaluated with a questionnaire based on the Cognitive Reserve Index questionnaire (CRIq) (Nucci et al., 2012; Szepietowska, 2019). Among others, the following issues were taken into account: current professional status, formal level of education, current and past activity in various areas of life. The CR index was the sum of points which covered the current professional status (professionally inactive $=0$ points, professionally active $=1$ point), level of education (basic $=1$ points, vocational $=2$ points, secondary $=3$ points, tertiary $=4$ points), areas of activity, each of whom was rated by the participants on a scale from 1 point (low intensity) to 5 points (very high intensity): physical, social and cognitive (past and present), independence in everyday life, selfesteem, support from others. The range of results was from 12 (low CR) to 60 points (high CR).

Cognitive functions were evaluated with:

1. Montreal Cognitive Assessment (MoCA) (Nasreddine et al., 2005). It is a screening tool for the detection of benign cognitive impairment, including short-term memory, visual-spatial, executive and language functions, attention, abstracting, and orientation. The maximum score is 30 points, and the result $\leq 26$ points suggests a decrease in cognitive performance.

2. Subtests from the Wechsler Adult Intelligence ScaleRevised (Brzeziński et al., 2004) - Vocabulary (a subtest which examins the ability to define concepts, considered by researchers as a measure of intelligence; maximum score is 70 points), Forward Digit Span and Backward Digit Span (subtests for short-term and operational memory testing, the maximum result in each of the subtests is 14 points).

3. Written Metaphor test in RHLB-PL (Right Hemisphere Language Battery) (Łojek, 2007), designed to assess abstract thinking and the ability to understand metaphors. It consists in choosing the correct meaning of the metaphor from the given variants. The maximum result is 10 points.

4. Semantic and emotional fluency tasks (Szepietowska and Gawda, 2011) which assess executive functions and semantic memory. The respondent's task is to generate as many words as possible according to a given criterion within one minute. In the semantic fluency test, the criterion is the semantic category ("animals"), and in the emotional fluency test, the respondent lists the words associated with the slogans "joy" (positive emotion) and "fear" (negative emotion). The analyses include the number of correctly produced words, i.e. words compliant with the criterion. świadomą zgodę na udział w badaniu (zgoda Komisji ds. Etyki Badań nr 13/2018). Kryteriami wykluczenia były: wywiad wskazujący na obciążenia psychiatryczne, złe samopoczucie osoby badanej, funkcjonowanie poznawcze uniemożliwiające wykonywanie testów. W analizach uwzględniono wyniki 30 osób w wieku 60-93 lat: 22 kobiet $\left(M_{\text {wiek }}=71,9\right.$; odchylenie standardowe, standard deviation, $S D=10,6)$ i 8 mężczyzn $\left(M_{\text {wiek }}=69,6 ; S D=6,7\right)$. Ponad połowa badanych miała wykształcenie średnie lub zawodowe $(66,7 \%)$, pozostałe osoby - wykształcenie wyższe $(26,7 \%)$ albo podstawowe $(6,7 \%)$. Większość uczestników $(86,7 \%)$ nie leczyła się i nie leczy z powodu obciążeń somatycznych i neurologicznych, w tym z powodu nadciśnienia tętniczego.

Do oceny CR wykorzystano kwestionariusz bazujący na Cognitive Reserve Index questionnaire (CRIq) (Nucci et al., 2012; Szepietowska, 2019). Uwzględniono m.in. aktualny status zawodowy, formalny poziom wykształcenia, aktualną i przeszłą aktywność w różnych obszarach życia. Wskaźnikiem CR była suma punktów, obejmująca aktualny status zawodowy (nieaktywny zawodowo $=0 \mathrm{pkt}$, aktywny $=1 \mathrm{pkt}$ ), poziom wykształcenia (podstawowe $=1$ pkt, zawodowe $=2$ pkt, średnie $=3$ pkt, wyższe $=4$ pkt), obszary aktywności, z których każdy oceniany był przez uczestników na skali od 1 pkt = niskie nasilenie do 5 pkt = bardzo wysokie nasilenie: aktywność fizyczna, społeczna i poznawcza (w przeszłości i aktualnie), samodzielność w życiu codziennym, samoocenę zdrowia, wsparcie ze strony innych. Zakres wyników wynosi od 12 (niska CR) do 60 punktów (wysoka CR).

Do oceny funkcji poznawczych posłużyły:

1. Montrealska Skala Oceny Funkcji Poznawczych (Montreal Cognitive Assessment, MoCA) (Nasreddine et al., 2005). Jest to narzędzie przesiewowe do wykrywania łagodnych zaburzeń poznawczych, obejmujące pamięć krótkotrwałą, funkcje wzrokowo-przestrzenne, wykonawcze i językowe, uwage, abstrahowanie, orientację. Maksymalny wynik to 30 pkt, a wynik $\leq 26$ pkt sugeruje obniżenie sprawności poznawczej.

2. Podtesty ze Skali Inteligencji D. Wechslera dla Dorosłych, wersji zrewidowanej (Brzeziński et al., 2004) - Słownik (podtest badający zdolność do definiowania pojęć, uważany przez badaczy również za miarę inteligencji; maksymalny wynik wynosi 70 pkt), Powtarzanie Cyfr Wprost i Wspak (podtesty do badania pamięci krótkotrwałej i operacyjnej, maksymalny wynik w każdym z podtestów to $14 \mathrm{pkt}$ ).

3. Test Metafor Pisanych z Baterii Testów do Badania Funkcji Językowych i Komunikacyjnych Prawej Półkuli Mózgu RHLB-PL (Right Hemisphere Language Battery) (Łojek, 2007), przeznaczony do oceny myślenia abstrakcyjnego i zdolności do rozumienia metafor. Polega na wybraniu poprawnego znaczenia metafory spośród podanych wariantów. Maksymalny wynik wynosi 10 pkt.

4. Próby fluencji semantycznej i emocjonalnej (Szepietowska i Gawda, 2011), oceniające funkcje wykonawcze 


\begin{tabular}{|c|c|c|c|}
\hline $\begin{array}{l}\text { Variables } \\
\text { Zmienne }\end{array}$ & $\begin{array}{c}\text { Polish } \\
\text { citizens } \\
\text { Obywatele } \\
\text { Polski } \\
(n=15)\end{array}$ & $\begin{array}{c}\text { Ukrainian } \\
\text { citizens } \\
\text { Obywatele } \\
\text { Ukrainy } \\
(\boldsymbol{n}=\mathbf{1 5})\end{array}$ & $\begin{array}{c}\chi^{2} \text { correlation } \\
\text { coefficients }(\boldsymbol{p}) \text { with } \\
\text { Yates' correction } \\
\text { Współczynniki korelaciji } x^{2}(p) \\
\text { z poprawkq Yatesa }\end{array}$ \\
\hline $\begin{array}{l}\text { Gender: } \\
\text { Płeć: } \\
\text { - female } \\
\text { kobiety } \\
\text { - male } \\
\text { mężczyźni } \\
\end{array}$ & $\begin{array}{c}n=10 \\
n=5\end{array}$ & $\begin{array}{l}n=12 \\
n=3\end{array}$ & $X^{2}=0.69(0.41)$ \\
\hline $\begin{array}{l}\text { Place of residence: } \\
\text { Miejsce zamieszkania: } \\
\text { - village } \\
\text { wieś } \\
\text { - city } \\
\text { miasto } \\
\end{array}$ & $\begin{array}{l}n=4 \\
n=11\end{array}$ & $\begin{array}{c}n=5 \\
n=10\end{array}$ & $X^{2}=0.16(0.69)$ \\
\hline $\begin{array}{l}\text { Education: } \\
\text { Wyksztakcenie: } \\
\text { - secondary } \\
\text { średnie } \\
\text { - vocational } \\
\text { zawodowe } \\
\text { - tertiary } \\
\text { wyższe }\end{array}$ & $\begin{array}{l}n=7 \\
n=5 \\
n=3\end{array}$ & $\begin{array}{l}n=4 \\
n=6 \\
n=5\end{array}$ & $x^{2}=1.41(0.49)$ \\
\hline $\begin{array}{l}\text { Medical history: } \\
\text { Obciqżenia } \\
\text { neurologiczne: } \\
\text { - yes } \\
\text { tak } \\
\text { - no } \\
\text { nie }\end{array}$ & $\begin{array}{c}n=2 \\
n=12\end{array}$ & $\begin{array}{c}n=2 \\
n=14\end{array}$ & $x^{2}=1.2(0.27)$ \\
\hline \multicolumn{4}{|c|}{$\begin{array}{l}Z \text { Zvalue for Student's } t \text {-test }(p) \\
\text { Wartość Z dla testu t-Studenta (p) }\end{array}$} \\
\hline $\begin{array}{l}\text { Age } \\
\text { Wiek }\end{array}$ & $\begin{array}{l}M=72.5 \\
S D=11.7\end{array}$ & $\begin{array}{l}M=70.1 \\
S D=7.3\end{array}$ & $0.67(0.51)$ \\
\hline $\begin{array}{l}\text { Years of education } \\
\text { Liczba lat edukacji }\end{array}$ & $\begin{array}{c}M=12.13 \\
S D=3.4\end{array}$ & $\begin{array}{l}M=11.47 \\
S D=3.71\end{array}$ & $0.79(0.61)$ \\
\hline $\begin{array}{l}\text { CR index } \\
\text { Wartość } C R\end{array}$ & $\begin{array}{l}M=42.53 \\
S D=8.27\end{array}$ & $\begin{array}{l}M=38.26 \\
S D=6.40\end{array}$ & $1.43(0.16)$ \\
\hline
\end{tabular}

Tab. 1. Demographic and clinical variables in sociopolitical groups (descriptive statistics, score comparisons, and $\chi^{2}$ correlation coefficients)

Tab. 1. Pochodzenie kulturowe a zmienne demograficzne i kliniczne (statystyki opisowe, porównania wyników oraz współczynniki korelacji $\chi^{2}$ )

5. Benton Visual Retention Test (Jaworowska, 2007), used to assess the storage and reproduction of visual material. For 10 seconds, the respondent is presented with a pattern, which the person is to reproduce as precisely as possible from memory after 10 seconds (version $\mathrm{C}$ ). The analysis includes the number of correct pattern reproductions. The maximum result is 10 points.

To assess the level of life satisfaction, the Satisfaction with Life Scale (SWLS) was used (Juczyński, 2009). The tool consists of five statements, assessed by the respondent on a seven-point scale. The obtained result is the result of comparing your own situation with the standards set by a given person. A higher score indicates a high sense of satisfaction with the quality of life. The Polish experimental version of the self-report questionnaire BDI-II (Beck Depression Inventory-II) was used to assess the intensity of a depressive mood (Beck et al., 1996; Szepietowska, 2019).

\begin{tabular}{|c|c|c|c|}
\hline $\begin{array}{l}\text { Variables } \\
\text { Zmienne }\end{array}$ & $\begin{array}{c}\text { Polish } \\
\text { citizens } \\
\text { Obywatele } \\
\text { Polski } \\
(n=15) \\
M(S D)\end{array}$ & $\begin{array}{c}\text { Ukrainian } \\
\text { citizens } \\
\text { Obywatele } \\
\text { Ukrainy } \\
(n=15) \\
M(S D)\end{array}$ & $\begin{array}{c}\boldsymbol{t} \text { value for } \\
\text { Student's } \boldsymbol{t} \text {-test } \\
\text { (p)/effect size } \\
\text { (Cohen's d) } \\
\text { Test t-Studenta (p)/ } \\
\text { wielkość efektu } \\
\text { (d Cohena) }\end{array}$ \\
\hline SWLS & $22.8(7.10)$ & $18.47(7.15)$ & $1.67(0.11)$ \\
\hline BDI-II & $15.27(7.57)$ & $11.93(8.48)$ & $1.14(0.27)$ \\
\hline $\begin{array}{l}\text { Vocabulary } \\
\text { Stownik }\end{array}$ & $39.4(14.8)$ & $41.3(16.9)$ & $-0.33(0.74)$ \\
\hline MoCA (total) & $24.93(4.44)$ & $22.13(3.22)$ & $1.97(0.06)^{* * *} / 0.721$ \\
\hline $\begin{array}{l}\text { - Visuospatial } \\
\text { subtest } \\
\text { podtest } \\
\text { Wzrokowo- } \\
\text { przestrzenny }\end{array}$ & $4.33(0.9)$ & $3.8(1.14)$ & $1.42(0.17)$ \\
\hline $\begin{array}{l}\text { - Naming } \\
\text { Nazywanie }\end{array}$ & $2.9(0.25)$ & $2.9(0.25)$ & $0.0(1.0)$ \\
\hline $\begin{array}{l}\text { - Attention } \\
\text { Uwaga }\end{array}$ & $4.57(1.8)$ & $4.9(1.03)$ & $-0.73(0.47)$ \\
\hline & $1.8(0.9)$ & $1.2(0.6)$ & $2.3(0.03)^{*} / 0.848$ \\
\hline $\begin{array}{l}\text { - Abstraction } \\
\text { Abstrahowanie }\end{array}$ & $1.67(0.62)$ & $0.8(0.77)$ & $3.38(0.002)^{* *} / 1.23$ \\
\hline $\begin{array}{l}\text { - Delayed Recall } \\
\text { Odroczone } \\
\text { przypominanie }\end{array}$ & $2.6(1.6)$ & $1.6(1.29)$ & $1.85(0.07)$ \\
\hline $\begin{array}{l}\text { - Orientation } \\
\text { Orientacja }\end{array}$ & $5.8(0.5)$ & $6.0(0)$ & $-1.00(0.33)$ \\
\hline $\begin{array}{l}\text { Fluency (total) } \\
\text { Fluencja (suma) }\end{array}$ & $30.33(8.62)$ & $26.2(11.15)$ & $1.14(0.03)^{*} / 0.411$ \\
\hline $\begin{array}{l}\text { Forward Digit Span } \\
\text { Cyfry Wprost }\end{array}$ & $5.27(1.22)$ & $6.20(1.31)$ & $\begin{array}{c}-2.009 \\
(0.05) * / 0.734 \\
\end{array}$ \\
\hline $\begin{array}{l}\text { Backward } \\
\text { Digit Span } \\
\text { Cyfry Wspak }\end{array}$ & $4.88(1.46)$ & $4.93(1.03)$ & $-0.14(0.88)$ \\
\hline $\begin{array}{l}\text { Benton Visual } \\
\text { Retention Test } \\
\text { Test Pamięci } \\
\text { Wzrokowej Bentona } \\
\end{array}$ & $5.53(1.45)$ & $4.3(1.7)$ & $2.06(0.05)^{*} / 0.783$ \\
\hline $\begin{array}{l}\text { Written Metaphor } \\
\text { test } \\
\text { Test Metafor } \\
\text { Pisanych }\end{array}$ & $8.9(2.31)$ & $8.3(2.05)$ & $0.75(0.45)$ \\
\hline
\end{tabular}

Tab. 2. Cognitive variables in groups of different cultural background (score comparisons and Cohen's $\mathrm{d}$ effect size)

Tab. 2. Zmienne poznawcze $w$ grupach o różnym pochodzeniu kulturowym (porównania wyników i wielkość efektu d Cohena)

i pamięć semantyczną. Zadaniem osoby badanej jest wygenerowanie jak największej liczby słów według określonego kryterium w ciągu jednej minuty. W próbie fluencji semantycznej kryterium stanowi kategoria semantyczna („zwierzęta”), a w próbie fluencji emocjonalnej badany wymienia słowa kojarzące się z hasłami „radość” (pozytywna emocja) i „strach” (negatywna emocja). W analizach uwzględniono liczbę poprawnie wyprodukowanych słów, czyli słów zgodnych z kryterium.

5. Test Pamięci Wzrokowej Bentona (Jaworowska, 2007), służący do oceny zapamiętywania i odtwarzania 


\begin{tabular}{|c|c|c|c|c|c|c|}
\hline \multirow[t]{2}{*}{$\begin{array}{l}\text { Variables } \\
\text { Zmienne }\end{array}$} & \multicolumn{2}{|c|}{$\begin{array}{c}\text { Polish citizens } \\
\text { Obywatele Polski } \\
(n=15) \\
M(S D)\end{array}$} & \multicolumn{2}{|c|}{$\begin{array}{c}\text { Ukrainian citizens } \\
\text { Obywatele Ukrainy } \\
(n=15) \\
M(S D)\end{array}$} & \multirow[t]{2}{*}{$F(p)$} & \multirow[t]{2}{*}{$\begin{array}{c}\eta_{p}^{2} \\
\text { Partial eta squared } \\
\text { Czqstkowe eta kwadrat }\end{array}$} \\
\hline & $\begin{array}{c}\text { Low CR } \\
\text { Niższy poziom } C R \\
\mathbf{3 2 . 7}(\mathbf{6 . 9}) \\
\boldsymbol{n}=\mathbf{4}\end{array}$ & $\begin{array}{c}\text { High CR } \\
\text { Wyższy poziom } C R \\
\mathbf{4 6 . 0}(\mathbf{5 . 5}) \\
\boldsymbol{n = 1 1}\end{array}$ & $\begin{array}{c}\text { Low CR } \\
\text { Niższy poziom } C R \\
\mathbf{3 3 . 6 ( 1 . 8 )} \\
\boldsymbol{n}=\mathbf{8}\end{array}$ & $\begin{array}{c}\text { High CR } \\
\text { Wyższy poziom } C R \\
\mathbf{4 4 . 3}(\mathbf{4 . 8 )} \\
\boldsymbol{n = 7}\end{array}$ & & \\
\hline $\begin{array}{l}\text { Vocabulary } \\
\text { Stownik }\end{array}$ & $38.8(17.7)$ & $39.6(14.7)$ & $41.6(17.8)$ & $41.0(17.5)$ & $0.04(0.99)$ & - \\
\hline SWLS & $21.5(5.3)$ & $23.3(7.8)$ & $18.8(8.1)$ & $18.1(6.5)$ & $0.93(0.44)$ & - \\
\hline $\begin{array}{l}\text { Fluency (total) } \\
\text { Fluencja (suma) }\end{array}$ & $29.0(5.8)$ & $30.8(9.6)$ & $24.4(9.7)$ & $28.2(13.0)$ & $0.62(0.61)$ & - \\
\hline $\begin{array}{l}\text { Forward Digit Span } \\
\text { Cyfry Wprost }\end{array}$ & $4.8(0.5)$ & $5.5(1.4)$ & $6.0(1.5)$ & $6.4(1.2)$ & $1.71(0.18)$ & - \\
\hline $\begin{array}{l}\text { Backward Digit Span } \\
\text { Cyfry Wspak }\end{array}$ & $4.0(1.4)$ & $5.2(1.4)$ & $4.9(1.1)$ & $5.0(1.0)$ & $0.89(0.46)$ & - \\
\hline $\begin{array}{l}\text { Benton Visual Retention Test } \\
\text { Test Pamięci Wzrokowej Bentona }\end{array}$ & $5.5(0.6)$ & $5.5(1.7)$ & $4.6(1.9)$ & $4.0(1.5)$ & $1.53(0.23)$ & - \\
\hline $\begin{array}{l}\text { Written Metaphor test } \\
\text { Test Metafor Pisanych }\end{array}$ & $9.5(0.6)$ & $8.7(2.7)$ & $7.5(2.3)$ & $9.3(1.3)$ & $1.17(0.34)$ & - \\
\hline $\begin{array}{l}\text { MoCA (total) } \\
\text { MoCA (suma) }\end{array}$ & $26.0(2.4)$ & $24.5(5.0)$ & $22.5(3.6)$ & $21.7(2.9)$ & $1.41(0.26)$ & - \\
\hline $\begin{array}{l}\text {-Visuospatial subtest } \\
\text { podtest Wzrokowo-przestrzenny }\end{array}$ & $4.3(1.0)$ & $4.4(0.9)$ & $4.0(1.1)$ & $3.6(1.3)$ & $0.85(0.48)$ & - \\
\hline $\begin{array}{l}\text { - Naming } \\
\text { Nazywanie }\end{array}$ & $3.0(0)$ & $2.9(0.3)$ & $2.9(0.3)$ & $3.0(0)$ & $0.40(0.75)$ & - \\
\hline $\begin{array}{l}\text { - Attention } \\
\text { Uwaga }\end{array}$ & $5.5(0.6)$ & $4.2(2.0)$ & $4.6(1.2)$ & $5.3(0.8)$ & $1.23(0.31)$ & - \\
\hline $\begin{array}{l}\text { - Language } \\
\text { Język }\end{array}$ & $2.0(0)$ & $1.7(1.1)$ & $0.9(0.6)$ & $1.4(0.5)$ & $2.43(0.06)^{*}$ & 0.22 \\
\hline $\begin{array}{l}\text { o cultural background } \\
\text { pochodzenie kulturowe }\end{array}$ & - & - & - & - & $\begin{array}{l}5.16(0.03)^{*} \\
P L>U A\end{array}$ & 0.16 \\
\hline$\circ C R$ & - & - & - & - & $0.21(0.66)$ & - \\
\hline $\begin{array}{l}\circ C R \times \text { cultural background } \\
C R \times \text { pochodzenie kulturowe }\end{array}$ & - & - & - & - & $1.74(0.19)$ & - \\
\hline $\begin{array}{l}\text { - Abstraction } \\
\text { Abstrahowanie }\end{array}$ & $1.8(0.5)$ & $1.6(0.7)$ & $0.9(0.8)$ & $0.7(0.8)$ & $3.67(0.02)^{*}$ & 0.29 \\
\hline $\begin{array}{l}\text { - cultural background } \\
\text { pochodzenie kulturowe }\end{array}$ & - & - & - & - & $\begin{array}{l}10.14(0.004)^{* *} \\
P L>U A\end{array}$ & 0.28 \\
\hline$\circ C R$ & - & - & - & - & $0.34(0.61)$ & - \\
\hline $\begin{array}{l}\text { - } C R \times \text { cultural background } \\
C R \times \text { pochodzenie kulturowe }\end{array}$ & - & - & - & - & $0.007(0.93)$ & - \\
\hline $\begin{array}{l}\text { - Delayed Recall } \\
\text { Odroczone przypominanie }\end{array}$ & $3.0(1.8)$ & $2.5(1.6)$ & $2.1(1.4)$ & $1.0(1.0)$ & $2.04(0.13)$ & - \\
\hline $\begin{array}{l}\text { - Orientation } \\
\text { Orientacja }\end{array}$ & $6.0(0)$ & $5.8(0.6)$ & $6.0(0)$ & $6.0(0)$ & $0.55(0.65)$ & - \\
\hline BDI-II & $15.8(9.3)$ & $15.1(7.4)$ & $17.8(7.7)$ & $5.3(1.3)$ & $4.69(0.009)^{* *}$ & 0.35 \\
\hline $\begin{array}{l}\text { - cultural background } \\
\text { pochodzenie kulturowe }\end{array}$ & - & - & - & - & $2.12(0.16)$ & - \\
\hline$\circ C R$ & - & - & - & - & $\begin{array}{c}5.99(0.02)^{*} \\
\text { High } C R<\text { lower } C R \\
\text { Wyższa } C R<\text { niższa } C R\end{array}$ & 0.19 \\
\hline
\end{tabular}

Tab. 3. Two-way analysis of variance of test results for CR level and cultural background (means, standard deviation, interaction of variables and effect size)

Tab. 3. Dwuczynnikowa analiza wariancji wyników testów dla zmiennych: poziom CR i pochodzenie kulturowe (średnie, odchylenia standardowe, interakcja czynników oraz wielkość efektu) 


\begin{tabular}{|c|c|c|c|c|c|c|}
\hline $\begin{array}{l}\text { - } C R \times \text { cultural background } \\
C R \times \text { pochodzenie kulturowe }\end{array}$ & - & - & - & - & 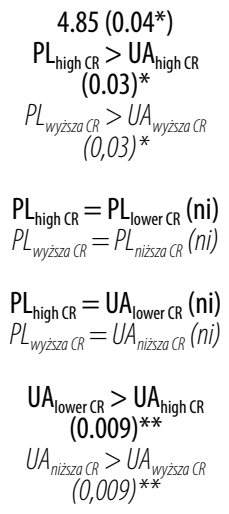 & 0.16 \\
\hline \multicolumn{7}{|c|}{$\begin{array}{l}\mathbf{P L}-\text { Polish citizens; UA - Ukrainian citizens. } \\
{ }^{*} p \leq 0.05 ;{ }^{* *} p \leq 0.01 ;{ }^{* * *} p \leq 0.06 \text { - level of statistical tendency. } \\
\mathbf{P L}-\text { obywatele Polski; UA - obywatele Ukrainy. } \\
{ }^{*} p \leq 0,05 ;{ }^{* *} p \leq 0,01 ;{ }^{* * *} p \leq 0,06-\text { poziom tendencji statystycznej. }\end{array}$} \\
\hline
\end{tabular}

Tab. 3. Two-way analysis of variance of test results for CR level and cultural background (means, standard deviation, interaction of variables and effect size) (cont.)

Tab. 3. Dwuczynnikowa analiza wariancji wyników testów dla zmiennych: poziom CR i pochodzenie kulturowe (średnie, odchylenia standardowe, interakcja czynników oraz wielkość efektu) (cd.)

\section{RESULTS}

The first stage of the analyses consisted in comparing the results obtained by respondents from Poland and Ukraine. In Tab. 1, demographic data is included, and in Tab. 2 - intergroup comparisons of results obtained in tasks aimed at assessing cognitive and emotional functions, and a sense of life satisfaction.

The groups did not differ significantly in terms of demographic data, CR level and the majority of results of tests on cognitive functions and a sense of life satisfaction (SWLS). The results obtained in SWLS indicated an average sense of life satisfaction in both groups $\left(5^{\text {th }}-6^{\text {th }}\right.$ sten $)$. Seniors from Poland were characterised with an (insignificantly) higher average results in many studied dimensions, which suggests a higher sense of life satisfaction, as well as higher CR and depressive mood (in the range from mild mood disorders to depression). Seniors from Ukraine performed insignificantly better in the Vocabulary subtest and Attention and Orientation MoCA subtests, and significantly better in Forward Digit Span. Polish seniors obtained a significantly higher overall score in MoCA, in terms of the number of words generated in verbal fluency tasks and the number of correct performances in the Benton Visual Retention Test, and in MoCA subtests: Language, Abstraction and Delayed Recall. The strengths of relationships between belonging to a group and performance of tasks were average and high. The performed correlation analyses showed that in both groups the CR score correlates with the intensity of depressive mood (Ukraine, $\rho_{\text {Spearman }}=-0.9, p \leq 0.001$, Poland $\left.\rho_{\text {Spearman }}=-0.5, p=0.03\right)$ : the higher severity of depression is connected with a less positive assessment of past and current life activity, included in the calculation of CR. In the Polish group, the stronger intensity of a depressive materiału wzrokowego. Osobie badanej przez 10 sekund prezentowany jest wzór, który ona ma za zadanie odtworzyć jak najdokładniej z pamięci po 10 sekundach (wersja C). W analizach uwzględniono liczbę poprawnych odtworzeń wzorów. Maksymalny wynik to 10 pkt. Do oceny poziomu satysfakcji z życia zastosowano Skalę Satysfakcji z Życia (Satisfaction with Life Scale, SWLS) (Juczyński, 2009). Narzędzie składa się z pięciu twierdzeń, ocenianych przez badanego na siedmiopunktowej skali. Uzyskany wynik jest rezultatem porównania własnej sytuacji z ustalonymi przez daną osobę standardami. Wyższy wynik wskazuje na wysokie poczucie zadowolenia z jakości życia. Do oceny nasilenia nastroju depresyjnego wykorzystano polską eksperymentalną wersję kwestionariusza samoopisowego BDI-II (Beck Depression Inventory-II, Kwestionariusz Depresji BDI-II Aarona T. Becka - drugie wydanie) (Beck et al., 1996; Szepietowska, 2019).

\section{WYNIKI}

Pierwszy etap analiz polegał na porównaniu wyników uzyskanych przez badanych z Polski i Ukrainy. W tab. 1 zawarto dane demograficzne, a w tab. 2 - międzygrupowe porównania wyników uzyskanych w zadaniach oceniających funkcje poznawcze i emocjonalne oraz poczucie satysfakcji z życia.

Grupy nie różniły się istotnie pod względem danych demograficznych, poziomu CR oraz większości wyników testów sprawdzających funkcje poznawcze i poczucie satysfakcji z życia (SWLS). Wyniki uzyskane w SWLS wskazują na przeciętne poczucie satysfakcji z życia w obydwu grupach (5.-6. sten). Seniorzy z Polski cechowali się w wielu badanych wymiarach (nieistotnie) wyższą średnią wyników, sugerującą wyższe poczucie satysfakcji z życia, a także 
mood is accompanied by a lower sense of quality of life (SWLS; $\rho_{\text {Spearman }}=-0.61, p=0.008$ ), and in the Ukrainian group, the greater efficiency of abstract thinking (RHLB metaphor) is accompanied by a more positive assessment of one's own resources $\left(\rho_{\text {Spearman }}=0.48, p=0.03\right.$ ).

The second stage of the analyses consisted in grouping all respondents in accordance to the level of their CR. Cluster analysis with $k$-means enabled distinguishing of two groups: people with a higher $(n=18, M=45.3, S D=5.2)$ and a lower $(n=12, M=33.3, S D=3.8 ; p \leq 0.001)$ CR level. It allowed to perform a series of two-factor analyses which took into account the following explanatory variables: 1) cultural background of respondents (Poland, Ukraine); 2) CR level (lower and higher), and an interactive influence of both variables on the explained variables - results in the next tests. On the basis of two variables (cultural background and $\mathrm{CR}$ ), four groups were distinguished: two groups of Poles, with a lower and a higher CR level, and two groups of seniors from Ukraine, with a lower and a higher CR level. The groups did not differ in terms of the number of years of education $(F=0.008, p=0.97)$ or age $(F=0.35, p=0.78)$. Other data (means, standard deviations, results of two-factor variance analyses) are presented in Tab. 3 .

The two-way variance analysis showed a significant effect of cultural origin and/or CR only in a few cases. The level of language skills (MoCA: Language) and abstract thinking (MoCA: Abstraction) was determined by the cultural factor, but not $C R$, whereas the depression mood intensity (BDI-II) - by CR and CR $\times$ cultural origin interaction. The cultural background explains $16 \%$ and $28 \%$ of the variance of the results in the mentioned MoCA subtests respectively, while $\mathrm{CR}$ and the $\mathrm{CR} \times$ cultural origin interaction explain $16 \%$ and $19 \%$ of the variance of results in BDI-II. People with higher CR (regardless of their cultural origin) were less depressed than people with lower CR $(p=0.02)$. The group $\times$ CR interaction showed that seniors from Ukraine with higher CR are characterised by a significantly lower intensity of depression compared to seniors from Poland with higher CR $(p=0.03)$ and seniors from Ukraine with lower CR $(p=0.009)$. In Poland, the CR (high/low) level did not differentiate the severity of depression. In relation to other cognitive skills, neither the CR nor the cultural origin nor the interaction of both analysed factors was observed.

\section{DISCUSSION}

Although the research presented in this paper is of a pilot character, it refers to a socially important issue - the importance of life activities and experiences that create $C R$ and are dependent on the cultural environment, for the current cognitive efficiency of a human being. The second objective of the research refers to the reflection on the methodology of the CR assessment.

In the author's own studies, there was no significant difference in the CR index between seniors from Poland and wyższy wskaźnik CR i nastroju depresyjnego (w granicach od łagodnych zaburzeń nastroju do depresji). Seniorzy z Ukrainy nieistotnie lepiej wykonali podtest Słownik oraz podtesty MoCA: Uwaga i Orientacja, natomiast istotnie lepiej - Cyfry Wprost. Polscy seniorzy uzyskali istotnie wyższy ogólny wynik w MoCA, w zakresie liczby wygenerowanych słów w zadaniach fluencji słownej i liczby poprawnych wykonań w Teście Pamięci Wzrokowej Bentona oraz w podtestach MoCA: Język, Abstrahowanie i Odroczone przypominanie. Siły związków między przynależnością do grupy a wykonaniem zadań są przeciętne i wysokie. Wykonane dodatkowo analizy korelacyjne wykazały, że w obu grupach wynik CR koreluje $\mathrm{z}$ nasileniem nastroju depresyjnego (Ukraina, $\rho_{\text {Spearmana }}=-0,9, p \leq 0,001$; Polska $\rho_{\text {Spearmana }}=-0,5$, $p=0,03$ ): wyższe nasilenie depresji ma związek z mniej pozytywną oceną przeszłej i aktualnej aktywności życiowej, uwzględnianej w obliczaniu CR. W grupie polskiej większemu nasileniu nastroju depresyjnego towarzyszy niższe poczucie jakości życia (SWLS; $\rho_{\text {spearmana }}=-0,61, p=0,008$ ), a w grupie ukraińskiej większa sprawność myślenia abstrakcyjnego (RHLB - metafory) towarzyszy bardziej pozytywnej ocenie własnych zasobów $\left(\rho_{\text {spearmana }}=0,48, p=0,03\right.$ ). Drugi etap analiz polegał na pogrupowaniu wszystkich badanych ze względu na poziom CR. Analiza skupień metodą $k$-średnich umożliwiła wyodrębnienie dwóch grup: osób $\mathrm{z}$ wyższym $(n=18 ; M=45,3, S D=5,2)$ i niższym $(n=12$; $M=33,3, S D=3,8 ; p \leq 0,001)$ poziomem CR. Pozwoliło to na wykonanie szeregu analiz dwuczynnikowych, uwzględniających jako zmienne wyjaśniające: 1) pochodzenie kulturowe badanych (Polska, Ukraina); 2) poziom CR (niższy i wyższy) oraz interakcyjny wpływ obydwu zmiennych na zmienne wyjaśniane - wyniki w następnych testach. Na podstawie dwóch zmiennych (pochodzenie kulturowe i CR) wyróżniono cztery grupy: dwie grupy Polaków, o niższym i wyższym poziomie $\mathrm{CR}$, oraz dwie seniorów z Ukrainy, o niższym i wyższym poziomie CR. Grupy nie różniły się pod względem liczby lat edukacji $(F=0,008$, $p=0,97)$ ani wieku $(F=0,35, p=0,78)$. Pozostałe dane (średnie, odchylenia standardowe, wyniki dwuczynnikowych analiz wariancji) przedstawiono w tab. 3.

Dwuczynnikowa analiza wariancji wykazała istotny wpływ pochodzenia kulturowego i/lub CR jedynie w kilku przypadkach. O poziomie sprawności językowej (MoCA: Język) i myślenia abstrakcyjnego (MoCA: Abstrahowanie) decydował czynnik kulturowy, ale nie $\mathrm{CR}$, natomiast o nasileniu nastroju depresyjnego (BDI-II) - CR oraz interakcja $\mathrm{CR} \times$ pochodzenie kulturowe. Pochodzenie kulturowe wyjaśnia odpowiednio $16 \%$ i $28 \%$ wariancji wyników $\mathrm{w}$ wymienionych podtestach MoCA, $\mathrm{z}$ kolei CR i interakcja $\mathrm{CR} \times$ pochodzenie kulturowe wyjaśniają $16 \%$ i $19 \%$ wariancji wyników w BDI-II.

Osoby mające wyższą CR (niezależnie od pochodzenia kulturowego) cechowały się mniejszym nasileniem depresji niż osoby o niższym poziomie CR $(p=0,02)$. Interakcja grupa $\times$ CR wykazała zaś, że seniorzy z Ukrainy z wyższą CR charakteryzują się istotnie 
in the tests. Intergroup comparisons of cognitive test results revealed sporadic differences between seniors, even though the groups were similar in terms of demographic data. Both groups, regardless of their country of origin, were characterised by a significant differentiation of results. For example, the standard deviation of the overall MoCA score ranged from almost the maximum to the low ( $<20$ points), suggesting the presence of cognitive deficits. These results confirm the heterogeneity of the cognitive performance in seniors (Mella et al., 2018).

The observed differences in the results of some cognitive tasks may be accidental and stem from a small number of respondents in groups. However, there are other possible explanations that should be included in the future research: different experience of the respondents connected to completing tests or a culturally conditioned way of selfdescription. It is also worth considering the specificity of development and school education, which, due to political conditions, were different in Poland and in Ukraine in the adolescence of the respondents. Early years of development directly shape cognitive abilities, but also determine the acquisition of other CR-forming competences (intellectual activity, professional work, social relations) (Tucker and Stern, 2011).

What deserves attention in intergroup comparisons, is a higher sense of life satisfaction and, at the same time, a higher depressive mood indicator among Poles. The data show that when the oldest age groups in various European countries (Ukraine excluded) are concerned, Polish seniors are among the most depressive ones (Czapiński and Błędowski, 2014). On the contrary, according to the author's own studies, the intensity of depressive mood turned out to be smaller among seniors from Ukraine, although the data indicate that the rate of depression in this country is more than four times higher than in other countries included by the World Health Organization (Tintle et al., 2011). However, both groups were characterised by a low to an average level of life satisfaction, which is in line with reports on the population of elderly people living in Ukraine (Pavlova et al., 2015) and in Poland (Witek and Błoński, 2015).

The main objective of the research was to determine the impact of CR and cultural origin on the current cognitive efficiency and emotional functioning. CR index and $\mathrm{CR} \times$ cultural background interaction significantly shaped the depression mood intensity, and cultural origin - the results in MoCA subtests: Language and Abstraction. The influence of the cultural origin on cognitive functioning can be explained, as mentioned earlier, with the specificity of education promoted in the time of the respondents' adolescence, which was aimed at acquiring general (secondary schools) or vocational (vocational schools) education. The issue of the relationship between CR and cultural background with the severity of depression is more complicated. The results show that the level of CR does not affect the severity of depression in Polish seniors. There is a significant difference between seniors with high CR from Poland mniejszym natężeniem depresji w porównaniu $\mathrm{z}$ seniorami z Polski z wyższą CR $(p=0,03)$ i seniorami z Ukrainy z niższą CR $(p=0,009)$. U Polaków poziom CR (wyso$\mathrm{ki} /$ niski) nie różnicował nasilenia depresji. W odniesieniu do innych sprawności poznawczych nie odnotowano wpływu ani CR, ani pochodzenia kulturowego, ani też interakcji obu analizowanych czynników.

\section{OMÓWIENIE}

Chociaż przedstawione tu badania mają charakter pilotażowy, nawiązują do istotnej społecznie kwestii - znaczenia aktywności i doświadczeń życiowych, tworzących CR i zależnych od środowiska kulturowego, dla aktualnej sprawności poznawczej człowieka. Drugi cel badań odnosi się do refleksji nad metodologią oceny CR.

W badaniach własnych wykazano brak istotnej różnicy w zakresie wskaźnika CR między seniorami z Polski i Ukrainy, choć ci drudzy uzyskali w testach nieco niższe wyniki. Międzygrupowe porównania wyników testów poznawczych ujawniły sporadyczne różnice między seniorami, mimo że grupy były wyrównane pod względem danych demograficznych. Obie grupy, niezależnie od kraju pochodzenia, cechowały się znaczącym zróżnicowaniem rezultatów. Przykładowo odchylenie standardowe ogólnego wyniku MoCA mieści się w przedziale od prawie maksymalnego do niskiego (<20 pkt), sugerującego obecność deficytów poznawczych. Rezultaty te potwierdzają heterogeniczność sprawności poznawczej osób w wieku senioralnym (Mella et al., 2018).

Odnotowane różnice w wynikach niektórych zadań poznawczych mogą być przypadkowe i mieć swoje źródło w niewielkiej liczebności grup. Są jednak możliwe i inne wyjaśnienia, które należy uwzględnić w przyszłych badaniach: różne doświadczenie osób badanych związane $\mathrm{z}$ wypełnianiem testów lub uwarunkowany kulturowo sposób samoopisu. Warto także uwzględnić specyfikę rozwoju i edukacji szkolnej, które w czasach młodości badanych, ze względu na warunki polityczne, w Polsce przebiegały odmiennie niż na Ukrainie. Wczesne lata rozwoju bezpośrednio kształtują zdolności poznawcze, ale też determinują nabywanie innych kompetencji tworzących CR (aktywność intelektualna, praca zawodowa, relacje społeczne) (Tucker i Stern, 2011).

W porównaniach międzygrupowych na uwagę zasługuje wyższe poczucie satysfakcji z życia, a zarazem wyższy wskaźnik nastroju depresyjnego u Polaków. Z danych wynika, że wśród najstarszych grup wiekowych w różnych krajach Europy (nie uwzględniono Ukrainy) polscy seniorzy należą do najbardziej depresyjnych (Czapiński i Błędowski, 2014). Z kolei u seniorów $\mathrm{z}$ Ukrainy nasilenie nastroju depresyjnego okazało się w badaniach własnych mniejsze, mimo że dane wskazują na ponad czterokrotnie wyższy wskaźnik depresji w tym kraju w porównaniu $z$ innymi uwzględnionymi przez Światową Organizację Zdrowia (Tintle et al., 2011). Jednak obie grupy cechowały się niskim do przeciętnego poziomem satysfakcji z życia, co pozostaje 
and Ukraine: the latter have a significantly lower depressive mood index. This result is in line with the observations by Kroemeke and Gruszczyńska (2014) and indicates a generally poor mental condition of elderly people in Poland in most cases, the authors recorded an increase in the severity of depression within one month. It is worth adding that a higher level of depression may translate into a negative assessment of one's past life and personal achievements. The relations in this respect are different in seniors from Ukraine: here the links between the low level of depression and the high level of CR, and the greater differentiation within the group of seniors were clearly outlined. According to Steptoe et al. (2007), the level of depression is determined by many correlated factors, not included in the author's own research, but reflecting cultural specificity: personal experiences and culturally shaped beliefs about the sense of life and one's own socioeconomic situation against the background of the general situation (larger dissonance promotes depression). This issue requires further analysis, but the results of the author's own research allow to discuss the significance of $\mathrm{CR}$ for cognitive functioning in the perspective of intercultural differences. It should be emphasised that the CR assessment included objective data, such as the level of formal education and professional activity, but also data obtained from the self-report regarding physical, social and leisure activities - now and in the past. In the ongoing discussion, the problem of CR measurement is emphasised. It is indicated that depending on the adopted indexes, different data on the impact of CR on the current cognitive functioning and on the prognostic role of $\mathrm{CR}$ in shaping cognitive performance in the subsequent years of life are obtained. According to Grotz et al. (2017), the retrospective assessment of some elements of CR (e.g. self-report of social or physical activity in adolescence) is carried out by subjectively-tested respondents through the prism of cultural experiences and patterns as well as in an incomplete or even erroneous manner, due to episodic memory deficits that increase with age (Kinugawa et al., 2013).

The variety of results obtained in the research on CR suggests that cognitive resources have a heterogeneous structure and ought to be considered as a combination of many factors of various importance for cognitive competence (Kaplan et al., 2009; Opdebeeck et al., 2016; Stern, 2002). Researchers underline the necessity of analysing experiences from particular periods of life, pointing to the greater role of early cognitive experiences in comparison to the adult life activity (Richards and Deary, 2005; Richards and Sacker, 2003). It is also necessary to take into account the qualitative aspect of education and work, which may pose tasks of various levels of difficulty to the individual (Ward et al., 2015).

\section{CONCLUSIONS}

The presented results suggest that the CR indexes may have different meanings for individual cognitive skills of seniors w zgodzie $\mathrm{z}$ doniesieniami na temat populacji starszych osób zamieszkujących na Ukrainie (Pavlova et al., 2015) oraz w Polsce (Witek i Błoński, 2015).

Zasadniczym celem badań było określenie wpływu CR i pochodzenia kulturowego na aktualną sprawność poznawczą i funkcjonowanie emocjonalne. Wskaźnik CR oraz interakcja $\mathrm{CR} \times$ pochodzenie kulturowe istotnie kształtowały nasilenie nastroju depresyjnego, a pochodzenie kulturowe - wykonanie podtestów MoCA: Język i Abstrahowanie. Wpływ pochodzenia kulturowego na funkcjonowanie poznawcze można wyjaśnić, jak wspomniano wcześniej, specyfiką edukacji promowanej w latach młodości uczestników, ukierunkowanej na nabywanie wiedzy ogólnej (licea) lub zawodowej (szkoły zawodowe). Kwestia związku CR i pochodzenia kulturowego z nasileniem depresji jest bardziej skomplikowana. Wyniki pokazują, że poziom CR nie ma wpływu na nasilenie depresji u polskich seniorów. Istnieje znamienna różnica między seniorami z wysoką CR z Polski i Ukrainy: ci drudzy mają istotnie niższy wskaźnik nastroju depresyjnego. Wynik ten jest zgodny z obserwacjami Kroemeke i Gruszczyńskiej (2014), wskazującymi na ogólnie złą kondycję psychiczną osób starszych w Polsce w większości przypadków autorki odnotowały wzrost nasilenia depresji w ciągu 1 miesiąca. Warto dodać, że wyższy poziom depresji może się przekładać na negatywną ocenę dotychczasowego życia i osobistych osiągnięć.

Inaczej kształtują się te relacje u seniorów z Ukrainy: tu wyraźnie zarysowały się związki między niskim poziomem depresji a wysokim poziomem CR oraz większe zróżnicowanie wewnątrz grupy seniorów. Jak podają Steptoe i wsp. (2007), o poziomie depresji decyduje wiele skorelowanych czynników, nieuwzględnionych w badaniach własnych, a odzwierciedlających specyfikę kulturową: osobiste doświadczenia i ukształtowane kulturowo przekonania na temat sensu życia oraz własna sytuacja społeczno-ekonomiczna na tle sytuacji ogólnej (większy rozdźwięk sprzyja depresji). Kwestia ta wymaga dalszych analiz, jednak wyniki badań własnych pozwalają dyskutować znaczenie CR dla funkcjonowania poznawczego w perspektywie różnic międzykulturowych. Należy przypomnieć, że w ocenie CR uwzględniano dane obiektywne, przykładowo poziom formalnego wykształcenia i aktywność zawodową, ale też dane uzyskane z samoopisu, dotyczące aktywności fizycznej, społecznej i podejmowanej w czasie wolnym - obecnie i w przeszłości. W trwającej dziś dyskusji akcentowany jest problem pomiaru CR. Wskazuje się, że zależnie od przyjętych wskaźników uzyskiwane są odmienne dane na temat wpływu CR na aktualne funkcjonowanie poznawcze oraz prognostycznej roli CR w kształtowaniu sprawności kognitywnej w kolejnych latach życia. Grotz i wsp. (2017) podkreślają, iż retrospektywna ocena niektórych elementów CR (np. samoopis aktywności społecznej lub fizycznej w młodości) jest dokonywana przez osoby badane subiektywnie, przez pryzmat doświadczeń i wzorców kulturowych, jak również w niepełny czy wręcz błędny sposób - w związku z narastającymi z wiekiem deficytami pamięci epizodycznej (Kinugawa et al., 2013). 
and their overall satisfaction with life. An important role is also played by the cultural environment, which creates the conditions for acquiring life experiences important for $\mathrm{CR}$ - this is about the specificity of school education or the availability of care and support for elderly people (for example social organizations, senior clubs). New challenges in the analysis of relations between CR and cognitive functioning are, on the one hand, sociocultural differences, and on the other - sociopolitical changes, migrations, merging of people from different cultures (Brucki and Nitrini, 2014). It is also necessary to take into account not only the level, but also the dynamics of cognitive skills in people with different levels of CR. Longitudinal studies will allow to observe the impact of CR on the process of cognitive aging and on human well-being in late adulthood.

\section{Conflict of interest}

The author does not declare any financial or personal relations with other people or organizations which may negatively influence the content of this publication or claim the right to this publication.

\section{References / Piśmiennictwo}

Armstrong MJ, Naglie G, Duff-Canning S et al.: Roles of education and IQ in cognitive reserve in Parkinson's disease-mild cognitive impairment. Dement Geriatr Cogn Dis Extra 2012; 2: 343-352.

Barnes DE, Covinsky KE, Whitmer RA et al.: Predicting risk of dementia in older adults: the late-life dementia risk index. Neurology 2009; 73: 173-179.

Beck AT, Steer RA, Ball R et al.: Comparison of Beck Depression Inventories -IA and -II in psychiatric outpatients. J Pers Assess 1996; 67: 588-597.

Börsch-Supan A, Brandt M, Hunkler C et al.: Data resource profile: the Survey of Health, Ageing and Retirement in Europe (SHARE). Int J Epidemiol 2013; 42: 992-1001.

Brucki SMD, Nitrini R: Cognitive impairment in individuals with low educational level and homogeneous sociocultural background. Dement Neuropsychol 2014; 8: 345-350.

Brzeziński J, Gaul M, Hornowska E et al.: Skala Inteligencji D. Wechslera dla Dorosłych. Wersja zrewidowana - renormalizacja WAIS-R(PL). Pracownia Testów Psychologicznych Polskiego Towarzystwa Psychologicznego, Warszawa 2004.

Byczewska-Konieczny K, Kielar-Turska M, Paleczna M: Znaczenie zasobów poznawczych dla poziomu funkcji zarządzających w wieku senioralnym. Psychologia Rozwojowa 2013; 18 (4): 83-93.

Cadar D, Robitaille A, Clouston S et al.: An international evaluation of cognitive reserve and memory changes in early old age in 10 European countries. Neuroepidemiology 2017; 48: 9-20.

Cadden MH, Guty ET, Arnett PA: Cognitive reserve attenuates the effect of disability on depression in multiple sclerosis. Arch Clin Neuropsychol 2019; 34: 495-502.

Cheng ST: Cognitive reserve and the prevention of dementia: the role of physical and cognitive activities. Curr Psychiatry Rep 2016; 18: 85.

Czapiński J, Błędowski P: Aktywność społeczna osób starszych w kontekście percepcji Polaków. Diagnoza społeczna 2013. Raport tematyczny. Ministerstwo Pracy i Polityki Społecznej i Centrum Rozwoju Zasobów Ludzkich, Warszawa 2014.

Darwish H, Farran N, Assaad S et al.: Cognitive reserve factors in a developing country: education and occupational attainment lower the risk of dementia in a sample of Lebanese older adults. Front Aging Neurosci 2018; 10: 277.

Eurostat - Statistics Explained: Struktura ludności i starzenie się społeczeństwa. Available from: https://ec.europa.eu/eurostat/sta-
Różnorodność wyników otrzymywanych w badaniach nad CR sugeruje, że ma ona niejednolitą strukturę i warto ją rozpatrywać jako kombinację wielu czynników o różnym znaczeniu dla kompetencji poznawczych (Kaplan et al., 2009; Opdebeeck et al., 2016; Stern, 2002). Badacze podkreślają konieczność analizy doświadczeń z poszczególnych okresów życia, wskazując na większą rolę wczesnych doświadczeń poznawczych w porównaniu $\mathrm{z}$ aktywnością życiową $\mathrm{w}$ dorosłości (Richards i Deary, 2005; Richards i Sacker, 2003). Trzeba też uwzględnić jakościowy aspekt edukacji i pracy zawodowej, które mogą stawiać przed jednostką zadania o różnym stopniu trudności (Ward et al., 2015).

\section{WNIOSKI}

Zaprezentowane wyniki sugerują, że wskaźniki CR mogą mieć różne znaczenie dla poszczególnych kompetencji poznawczych seniorów oraz ich ogólnej satysfakcji z życia. Istotną rolę odgrywa również środowisko kulturowe, które stwarza warunki do nabywania doświadczeń życiowych istotnych dla CR - mowa tu o specyfice edukacji szkolnej czy dostępności opieki i wsparcia dla osób starszych (przykładowo: organizacje społeczne, kluby seniora). Nowymi wyzwaniami $\mathrm{w}$ analizach relacji między $\mathrm{CR}$ a funkcjonowaniem poznawczym są z jednej strony różnice socjokulturowe, a z drugiej przemiany społeczno-polityczne, migracje, łączenie się osób pochodzących z odmiennych kultur (Brucki i Nitrini, 2014). Konieczne jest ponadto uwzględnienie nie tylko poziomu, lecz także dynamiki kompetencji poznawczych u osób o różnym poziomie CR. Badania podłużne pozwolą zaobserwować wpływ CR na proces poznawczego starzenia się i na dobrostan człowieka w okresie późnej dorosłości.

\section{Konflikt interesów}

Autorka nie zglasza żadnych finansowych ani osobistych powiązań z innymi osobami lub organizacjami, które mogtyby negatywnie wplynać na treść publikacji oraz rościć sobie prawo do tej publikacji.

tistics-explained/index.php/Population_structure_and_ageing/pl [cited: 23 May 2019].

Farfel JM, Nitrini R, Suemoto CK et al.; Brazilian Aging Brain Study Group: Very low levels of education and cognitive reserve: a clinicopathologic study. Neurology 2013; 81: 650-657.

Fyffe DC, Mukherjee S, Barnes LL et al.: Explaining differences in episodic memory performance among older African Americans and Whites: the roles of factors related to cognitive reserve and test bias. J Int Neuropsychol Soc 2011; 17: 625-638.

Grotz C, Seron X, Van Wissen M et al.: How should proxies of cognitive reserve be evaluated in a population of healthy older adults? Int Psychogeriatr 2017; 29: 123-136.

Ihle A, Oris M, Sauter J et al.: Cognitive reserve and social capital accrued in early and midlife moderate the relation of psychological stress to cognitive performance in old age. Dement Geriatr Cogn Disord 2018; 45: 190-197.

Jaworowska A: Test Pamięci Wzrokowej Bentona: polska normalizacja. Pracownia Testów Psychologicznych Polskiego Towarzystw Psychologicznego, Warszawa 2007. 
Juczyński Z: Narzędzia pomiaru w promocji i psychologii zdrowia. Pracownia Testów Psychologicznych Polskiego Towarzystw Psychologicznego, Warszawa 2009.

Kalaria RN, Maestre GE, Arizaga R et al.; World Federation of Neurology Dementia Research Group: Alzheimer's disease and vascular dementia in developing countries: prevalence, management, and risk factors. Lancet Neurol 2008; 7: 812-826.

Kaplan RF, Cohen RA, Moscufo N et al.: Demographic and biological influences on cognitive reserve. J Clin Exp Neuropsychol 2009; 31: 868-876.

Kinugawa K, Schumm S, Pollina M et al.: Aging-related episodic memory decline: are emotions the key? Front Behav Neurosci 2013; 7: 2 .

Kroemeke A, Gruszczyńska E: Depressive symptom clusters among the elderly: a longitudinal study of course and its correlates. Health Psychology Report 2014; 2: 269-279.

Kupets O: Labor market challenges of an aging and shrinking population in Ukraine. JCES 2014; 9: 99-134.

Lara E, Koyanagi A, Caballero F et al.: Cognitive reserve is associated with quality of life: A population-based study. Exp Gerontol 2017; 87: 67-73.

Łojek E: Bateria Testów do Badania Funkcji Językowych i Komunikacyjnych Prawej Półkuli Mózgu RHLB-PL. Pracownia Testów Psychologicznych Polskiego Towarzystwa Psychologicznego, Warszawa 2007.

Malek-Ahmadi M, Lu S, Chan Y et al.: Static and dynamic cognitive reserve proxy measures: interactions with Alzheimer's disease neuropathology and cognition. J Alzheimers Dis Parkinsonism 2017; 7. pii: 390 .

Mella N, Fagot D, Renaud O et al.: Individual differences in developmental change: quantifying the amplitude and heterogeneity in cognitive change across old age. J Intell 2018; 6: 10.

Meng X, D'Arcy C: Education and dementia in the context of the cognitive reserve hypothesis: a systematic review with meta-analyses and qualitative analyses. PLoS One 2012; 7: e38268.

Murphy M, O'Leary E: Depression, cognitive reserve and memory performance in older adults. Int J Geriatr Psychiatry 2010; 25: 665-671.

Nasreddine ZS, Phillips NA, Bédirian V et al.: The Montreal Cognitive Assessment, MoCA: a brief screening tool for mild cognitive impairment. J Am Geriatr Soc 2005; 53: 695-699.

Nucci M, Mapelli D, Mondini S: Cognitive Reserve Index questionnaire (CRIq): a new instrument for measuring cognitive reserve. Aging Clin Exp Res 2012; 24: 218-226.

Ojagbemi A, Bello T, Gureje O: Cognitive reserve, incident dementia, and associated mortality in the Ibadan Study of Ageing. J Am Geriatr Soc 2016; 64: 590-595.

Opdebeeck C, Kudlicka A, Nelis S et al.: Cognitive reserve is associated with quality of life, self-esteem, and self-efficacy in later life. Innov Aging 2017; 1 (Suppl 1): 877-878.

Opdebeeck C, Martyr A, Clare L: Cognitive reserve and cognitive function in healthy older people: a meta-analysis. Neuropsychol Dev Cogn B Aging Neuropsychol Cogn 2016; 23: 40-60.

Paulson D, Bowen ME, Lichtenberg PA: Does brain reserve protect older women from vascular depression? J Gerontol B Psychol Sci Soc Sci 2014; 69: 157-167.
Pavlova I, Vynogradsky B, Borek Z et al.: Life quality and physical activity of Ukrainian residents. JPES 2015; 15: 809-814.

Prince M, Bryce R, Albanese E et al.: The global prevalence of dementia: a systematic review and metaanalysis. Alzheimers Dement 2013; 9: 63-75.e2.

Richards M, Deary IJ: A life course approach to cognitive reserve: A model for cognitive aging and development? Ann Neurol 2005; 58: 617-622.

Richards M, Sacker A: Lifetime antecedents of cognitive reserve. J Clin Exp Neuropsychol 2003; 25: 614-624.

Rizzi L, Rosset I, Roriz-Cruz M: Global epidemiology of dementia: Alzheimer's and vascular types. Biomed Res Int 2014; 2014: 908915.

Scarmeas N, Stern Y: Cognitive reserve and lifestyle. J Clin Exp Neuropsychol 2003; 25: 625-633.

Singh-Manoux A, Marmot MG, Glymour M et al.: Does cognitive reserve shape cognitive decline? Ann Neurol 2011; 70: 296-304.

Šneidere K, Montemurro S, Mondini S et al.: Cognitive reserve and cognitive performance in healthy Latvian seniors. Society. Integration. Education. Proceedings of the International Scientific Conference 2018: 7: 261-269.

Starr JM, Lonie J: Estimated pre-morbid IQ effects on cognitive and functional outcomes in Alzheimer disease: a longitudinal study in a treated cohort. BMC Psychiatry 2008; 8: 27.

Steptoe A, Tsuda A, Tanaka Y et al.: Depressive symptoms, socio-economic background, sense of control, and cultural factors in university students from 23 countries. Int J Behav Med 2007; 14: 97-107.

Stern Y: Cognitive reserve. Neuropsychologia 2009; 47: 2015-2028.

Stern Y: What is cognitive reserve? Theory and research application of the reserve concept. J Int Neuropsychol Soc 2002; 8: 448-460.

Stern Y, Habeck C, Moeller J et al.: Brain networks associated with cognitive reserve in healthy young and old adults. Cereb Cortex 2005; 15: 394-402.

Szepietowska EM: Cognitive reserve as a factor determining the level of cognitive functions in adults: a preliminary report. Psychiatr Psychol Klin 2019; 19: 32-41.

Szepietowska EM, Gawda B: Ścieżkami fluencji werbalnej. Wydawnictwo UMCS, Lublin 2011.

Tintle N, Bacon B, Kostyuchenko S et al.: Depression and its correlates in older adults in Ukraine. Int J Geriatr Psychiatry 2011; 26: 1292-1299.

Tucker AM, Stern Y: Cognitive reserve in aging. Curr Alzheimer Res 2011; 8: 354-360.

Ward DD, Summers MJ, Saunders NL et al.: Modeling cognitive reserve in healthy middle-aged and older adults: the Tasmanian Healthy Brain Project. Int Psychogeriatr 2015; 27: 579-589.

Witek J, Błoński K: Ocena jakości życia osób starszych w Polsce na podstawie European Quality of Life Surveys. Handel Wewnętrzny 2015; 5 (358): 410-424.

World Health Organization: World Report on Ageing and Health. WHO Library Cataloguing-in-Publication Data, Geneva 2015. 